\title{
Fatigue delamination behaviour of unidirectional carbon fibre/epoxy laminates reinforced by Z-Fiber ${ }^{\circledR}$ pinning
}

Denis D. R. Cartié ${ }^{1}$, Jean-Martin Laffaille ${ }^{1}$, Ivana K. Partridge ${ }^{1}$ and Andreas J.

Brunner ${ }^{2}$

1 - Composites Centre, School of Applied Sciences, Cranfield University, MK43 OAL, UK

2 - Empa, Swiss Federal Laboratories for Materials Testing and Research $\mathrm{CH}-8600$

Dübendorf, Switzerland

\begin{abstract}
:
Z-pin reinforced carbon-fibre epoxy laminates were tested under Mode I and Mode II conditions, both quasi-statically and in fatigue. Test procedures were adapted from existing standard or pre-standard tests. Samples containing $2 \%$ and $4 \%$ areal densities of carbonfibre Z-pins (0.28 mm diameter) were compared with unpinned laminates. Quasi-static tests under displacement control yielded a dramatic increase of the apparent delamination resistance. Specimens with $2 \%$ pin density failed in Mode I at loads $170 \mathrm{~N}$, equivalent to an apparent $G_{I C}$ of $2 \mathrm{~kJ} / \mathrm{m}^{2}$. Fatigue testing under load control showed that the presence of the through-thickness reinforcement slowed down fatigue delamination propagation .
\end{abstract}

\section{Keywords:}

Composites, Delamination, Fatigue crack growth, Z-Fiber® pinning

\section{Introduction:}

The proportion of composite structures is increasing in all applications where weight is critical. A major effort of the composite industry has focused on eliminating the inherent weakness of composite materials, namely low delamination resistance. Solutions to improve interlaminar toughness include toughening of the resin, resin interleaving, and more recently through the thickness reinforcement including 3D weaving, stitching, tufting and Z-Fiber $\circledast$ pinning.

Z-Fiber ${ }^{\circledR}$ pinning (thereafter referred to as Z-pinning) is the only technique suitable for the reinforcement of structures manufactured using the prepreg/autoclave route. Mouritz recently reviewed the effect of Z-pins on composite laminates [1]. The effectiveness of Z-pins to increase delamination resistance [2-9] , impact damage tolerance [10-11] and joint strength [12-14] has been demonstrated clearly using both experimental and modelling approaches. However, not all effects of Z-pinning are positive. The improvement of interlaminar properties comes with a reduction of the in-plane elastic properties (modulus, strength and fatigue 
performance) [15-19]. For example, Steeves and Fleck reported a drop of compressive strength of at least $30 \%$ [19]. Because of this reduction of the in-plane properties, the use of $Z$-pins is limited to the reinforcement of those structures likely to fail by delamination. So far, the use of Z-pins is limited to military aerospace application (F18E/F) [20] and Formula 1 racing [21]. In his review, Mouritz states that a number of issues such as durability, modelling of structural behaviour and low cost manufacturing need to be resolved before using Zpinning to its full potential in civil aerospace applications [1]. This paper reports a study of the delamination behaviour of Z-pin laminates under Mode I and Mode II fatigue loading conditions. The results are related to the apparent toughness values obtained under quasistatic Mode I and Mode II loadings.

\section{Materials}

The results reported in this paper were obtained by testing laminates made from AS4B/8552 prepreg supplied by Hexcel Composites (UK). Thirty two plies of this prepreg were hand laidup, achieving a nominal laminate thickness of $4 \mathrm{~mm}$. A $10 \mu \mathrm{m}$ PTFE film was inserted in the mid-plane to act as a delamination initiator.

After a final debulk at $50^{\circ} \mathrm{C}$ for $30 \mathrm{~min}$, the plate was reinforced locally using T300/BMI Z-pins of $0.28 \mathrm{~mm}$ diameter . The Z-pins were inserted at two different volume densities: $2 \%$, giving a pin-to-pin spacing of $1.8 \mathrm{~mm}$ and $4 \%$, giving a pin-to-pin spacing of $1.2 \mathrm{~mm}$. The following convention will be used throughout the paper: un-reinforced specimens (control) will be designated $0 \%$, samples reinforced with Z-pins inserted at a density of $2 \%$ ( $4 \%$ ) will be designated $2 \%(4 \%)$. The Z-pins were inserted using the UAZ ${ }^{\mathrm{TM}}$ (Ultrasonically Assisted ZFiber $\left.{ }^{\circledR}\right)$ process described in references [1] and [2].

Fig. 1 shows a typical Z-pinned specimen configuration. A $50 \mathrm{~mm}$ long band of Z-pins was inserted $15 \mathrm{~mm}$ beyond the end of the starter film. After insertion of the reinforcement and subsequent removal of the excess pin length, the laminate was cured in an autoclave at $180^{\circ} \mathrm{C}$ under 7 bar pressure for 2 hours, after a dwell of 1 hour at $110^{\circ} \mathrm{C}$.

Caul plates (top and bottom) were used during cure to ensure good laminate consolidation and low thickness variation near the Z-pinned area. As a consequence, the pins have tilted during the compaction of the laminate during the cure, resulting in a pin angle between $20^{\circ}$ and $35^{\circ}$. It is important to note that the pins are not normal to the plane of the laminate as this may have an effect on the phenomena reported in this paper.

After cure, a dry diamond coated circular saw was used to cut $20 \mathrm{~mm}$ wide samples for quasistatic testing and $25 \mathrm{~mm}$ wide samples for testing under fatigue loading conditions. 


\section{Experimental}

\subsection{Test methods}

\subsubsection{Mode I}

The quasi-static tests were performed following the procedure described in ISO15024 [22] at a constant cross-head speed of $2 \mathrm{~mm} / \mathrm{min}$. All results were first analysed using the corrected beam theory. The data reduction uses a crack length correction factor, $\Delta^{1}$. This correction factor is added to the crack length in order to account for the deformation in the beam beyond the crack tip. Results from the Z-pinned samples were re-analysed using two different analysis schemes suggested by Robinson and Das [23] and Brunner et al. [24]. The results will be shown and discussed in the following section.

Mode I fatigue tests were performed following a protocol developed recently within the ESIS TC4 committee by Pinter [25]. This test procedure is intended for unidirectionally reinforced fibre laminates without through-thickness reinforcement. For preliminary tests with this procedure, both displacement and load control were defined. Specimens are first precracked from the insert film under quasi-static load (displacement control), and subsequently displacement control loading is used for fatigue. Finally testing switches to load-control fatigue for comparison of the two control modes. (N.B. it is likely that displacement control only will be implemented in the final procedure.) Recommended test frequency is $10 \mathrm{~Hz}$, with an Rratio of 0.1 , if possible for the specific material and test set-up. Lower frequencies are admissible, but will increase test duration. Delamination propagation is observed visually with the aid of a travelling microscope. Samples may not be removed from the test fixture during the test.

\subsubsection{Mode II}

Quasi-static delamination testing under Mode II loading conditions was performed following the corrected ELS protocol developed within the ESIS TC4 [26]. This procedure is currently investigated in round robin tests and first results indicate reasonable agreement for unpinned, unidirectionally reinforced fibre laminates [27]. The quasi-static tests were carried out at a constant cross-head speed of $0.5 \mathrm{~mm} / \mathrm{min}$. The compliance of the test set-up was measured using the 'inverse ELS' procedure. The test data were then analysed using the corrected beam theory.

Mode II fatigue tests were performed with the same ELS test set-up used for the quasi-static tests. Test parameters were adapted from the ESIS TC4 procedure for Mode I fatigue testing (R-ratio set to 0.1 , test frequency of 5 to $10 \mathrm{~Hz}$ desired, effectively as high as possible). Again, fatigue tests on Z-pinned samples were performed under load control only.

1 The $\Delta$ factor is the $Y=0$ intercept of the plot of $\left(C / M^{1 / 3}\right.$ vs. $a$, where $C / N$ is the corrected compliance and $a$ the crack length (see [22] for more information). 


\subsection{Test set-up and parameters}

Quasi-static and fatigue tests in Mode I and Mode II were mainly performed at one laboratory, with selected fatigue tests performed for the purpose of comparison in the co-author's laboratory. For the fatigue tests, $0 \%$ pin reinforcement samples were tested under displacement control and Z-pinned samples were tested under load control. Specimens were either tested from the insert starter film or from a precrack created by a quasi-static test. Load levels for the fatigue tests were chosen comparable to the loads observed during quasistatic tests. If delamination propagation was observed to slow down and virtually stop in the Z-pinned area of the specimen, the load level was increased and the test continued.

Laboratory $\mathrm{A}$, equipped with climate control at $+23^{\circ} \mathrm{C}$ and $50 \%$ relative humidity, performed fatigue tests on Z-pinned specimens using a servo-hydraulic test machine (Instron type 1273) with a $1 \mathrm{kN}$ load cell calibrated in the load range up to $200 \mathrm{~N}$. Fatigue tests have were performed with frequencies between 1 and $5 \mathrm{~Hz}$ under load control, the R-ratio was set to 0.1 . With increasing load levels, the test frequency had to be lowered (from 5 to 3 , to 2 , and finally to $1 \mathrm{~Hz}$ ) in order to achieve the corresponding displacement. Delamination lengths were monitored with a travelling microscope with magnification of 16 times at selected intervals. Fatigue loading was stopped for this, but the specimen was not removed from the fixture. As a check on the test, machine data (maximum and minimum load and displacement per cycle) were recorded every 5'000 and 10'000 cycles in the early and later stages of the test, respectively.

Laboratory B used screw driven Zwick ZN10 with a $2 \mathrm{kN}$ load cell to perform the quasi-static DCB and ELS tests. The fatigue tests were carried out using a servo-hydraulic DMS machine with a $10 \mathrm{kN}$ load cell calibrated on the $2 \mathrm{kN}$ range. The maximum frequency achievable with this machine was $1 \mathrm{~Hz}$. As for laboratory $\mathrm{A}$, the R-ratio was set at 0.1 and the delamination growth was monitored visually using a travelling microscope. A specially designed Labview programme was used to record the compliance, the maximum and minimum loads and displacements every 1000 cycles.

Laboratory A used fixed load levels of $50 \mathrm{~N}$ for testing from the insert or precrack until the delamination propagation stopped in the Z-pinned area. Then, the load was increased in steps of $50 \mathrm{~N}$ (i.e., first to $100 \mathrm{~N}$, then to $150 \mathrm{~N}$, and so on) until a failure of the specimen was observed or the test stopped. A few specimens with nominal width of $20 \mathrm{~mm}$ were also tested in fatigue. The load levels were scaled with the width for these specimens. 


\section{Results}

\subsection{Quasi-static tests}

\subsubsection{Mode I}

Fig. 2 shows the resistance curves of all Mode I tests, with and without Z-pins, analysed using the standard corrected beam theory. Control samples exhibit relatively flat R-curves at an average propagation value of around $310 \mathrm{~J} / \mathrm{m}^{2}$.

For all samples, the first $15 \mathrm{~mm}$ of crack propagation was through an area which did not contain Z-pins. The apparent toughness ${ }^{2}$ for all samples ranges from 210 to $280 \mathrm{~J} / \mathrm{m}^{2}$. As the delamination crack approaches the through-thickness reinforcement, the load increases and the apparent toughness increases dramatically. It is noticed that this increase occurs 2 to 3 $\mathrm{mm}$ before the delamination front reaches the Z-pins. The first row of Z-pins is located nominally at $65 \mathrm{~mm}$ from the load line.

In the case of $2 \%$ density reinforcement the crack continues to grow through the Z-pinned area (see Fig. 3-a) and a plateau value of the apparent toughness is reached $\left(5.1 \mathrm{~kJ} / \mathrm{m}^{2}\right.$ on average). The crack propagation behaviour within the Z-pinned area is variable, depending on the local 3D architecture. Some specimens exhibited stable crack propagation at high toughness levels. Some others exhibited stick-slip behaviour. Once the crack has passed the pinned area, the crack propagation becomes unstable and the specimen fails by complete delamination as observed by the authors in previous work [2, 3]. Such unstable crack propagation could be stopped effectively by a suitably located second Z-pinned area, as shown previously by Cartié et al. [4].

In the case of the $4 \%$ density reinforcement, the apparent toughness increases to a level of approximately $10 \mathrm{~kJ} / \mathrm{m}^{2}$. Eventually the crack is stopped by the Z-pin bridging actions and the specimen fails by flexure in the beam arms (see Fig.3-b).

\subsubsection{Mode II}

Blackman and co-authors have demonstrated that the ELS test is stable provided that the ratio of the crack length divided by the initial span $(a / L)$ is greater than $0.55^{3}$. Despite an initial $(a / L)$ ratio of 0.6 , the ELS tests performed on the control samples were unstable. The initial loading was linear elastic to failure. The crack propagated to a final length of approximately $90 \mathrm{~mm}$, only $10 \mathrm{~mm}$ away from the clamping fixture. No propagation data were recorded; therefore no propagation toughness values could be determined. The corresponding initiation toughness value was $980 \mathrm{~J} / \mathrm{m}^{2}$.

$2 \quad$ Calculated using the standard corrected beam theory taking an average of the propagation points excluding the initiation points.

3 The stability of the test is defined by $\frac{\partial G_{I I}(a, \delta)}{\partial a} \leq 0$, which is equivalent to $a / L \geq \sqrt[3]{6} \approx 0.55$ where $a$ is the crack length and $L$ the loading span. 
The Z-pinned samples exhibited similar initial unstable crack propagation behaviour within the non-reinforced area. In the unpinned area, the initiation values were $950 \mathrm{~J} / \mathrm{m}^{2}$ for the $2 \%$ reinforcement and $910 \mathrm{~J} / \mathrm{m}^{2}$ for the $4 \%$ pin density, on average. The unstable crack propagated a few millimetres within the pinned area before being stopped by the action of the Z-pins.

With continuing loading, the crack growth behaviour of the samples containing $2 \%$ reinforcement was stable until the crack reached the clamping fixture. The tests were stopped at this point. After data reduction using the corrected beam theory, the resistance curve is continuously rising, until the end of the tests. No steady state propagation was reached. The apparent toughness value at this point is in the region of $7.3 \mathrm{~kJ} / \mathrm{m}^{2}$. In the $4 \%$ pin density samples, the crack never re-started and the specimen failed in flexure similarly to the Mode I samples. Using the beam theory, the apparent toughness at the time of failure was in excess of $9 \mathrm{~kJ} / \mathrm{m}^{2}$.

\subsection{Fatigue tests}

\subsubsection{Mode I}

The results of fatigue delamination testing are presented in terms of crack growth rate ( $d a / d M)$ versus applied $G_{I \max }$ (Fig. 4 to Fig. 6). The $G_{I \max }$ is calculated with the direct beam theory corrected for large displacement and load block effects using equation 1. An initial investigation of the determination of the crack length correction factor $\Delta$, using regression analysis of the data points from fatigue tests, showed high scatter.

$$
G_{\operatorname{Im} a x}=\frac{3 P_{\max } \delta_{\max }}{2 b a} \frac{F}{N} \quad \text { equation } 1
$$

Here, $P_{\max }$ (resp. $\delta_{\max }$ ) is the applied maximum load (resp. displacement), $b$ is the width of the specimen and $a$ the crack length measured by visual observation. $F$ and $N$ are same the correction factors for large displacement and finite displacement correction to account for the load block effects as for quasi-static testing. The expression of $F$ and $N$ can be found in [22].

Fig. 4 shows the delamination fatigue behaviour of two control specimens tested under displacement control loading conditions (filled symbols) as well as the behaviour of four Zpinned specimens loaded under force control loading conditions with a maximum applied load of $50 \mathrm{~N}$ (open symbols).

Under displacement control, $\partial G(a, \delta) / \partial a \leq 0$. This means that during testing, as the crack propagates under constant maximum applied displacement, the applied $G_{\operatorname{lmax}}$ decreases. In practical terms, while the loading is oscillating between $\delta_{\min }$ and $\delta_{\max }$ (both of which are fixed) the crack propagates and the applied $G_{\max }$ decreases: with decreasing loading, the crack 
growth rate is expected to decrease. The curve is followed from right to left (grey arrow in Fig. 4). The control specimens follow a typical Paris-like behaviour, similar to that observed by Brunner et al [30].

Under load control, $\partial G(a, P) / \partial a \geq 0$. In this case, as the crack propagates under constant maximum applied load, the applied $G_{\operatorname{lmax}}$ increases. The crack propagation is expected to accelerate and $d a / d N$ is expected to increase. This acceleration is observed in Figure 4 in the Z-pinned samples while the crack was propagating in the initial unpinned area. Looking at the open symbols, it can be observed that the crack growth rate increases from $10^{-5}$ to $10^{-4}$ $\mathrm{mm} /$ cycles for loading increasing from approximately $100 \mathrm{~J} / \mathrm{m}^{2}$ to $130 \mathrm{~J} / \mathrm{m}^{2}$ (highlighted by the arrow marked load control 0\% in Fig. 4).

When the crack front reaches the pinned area, despite an increasing applied load, the crack propagation slows down. For all four samples containing through-thickness reinforcement, the crack growth rates decrease to below $10^{-6} \mathrm{~mm} /$ cycles for a similar $G_{I \max }$ of $170 \mathrm{~J} / \mathrm{m}^{2}$.

Fig. 5 shows the behaviour of a specimen containing $2 \%$ areal density pins when $P_{\max }$ was increased to $55 \mathrm{~N}$ and later to $65 \mathrm{~N}$. With the step increase in the load, crack propagation initially re-starts. In both cases, due to the action of the pins in the crack wake, $d a / d N$ then decreases, the crack propagation slows down. At $P_{\max }=55 \mathrm{~N}\left(G_{\max }\right.$ of $\left.210 \mathrm{~J} / \mathrm{m}^{2}\right)$, the crack growth rate decreases to $10^{-6} \mathrm{~mm} /$ cycles in approximately 80,000 cycles. At $P_{\max }=65 \mathrm{~N}$ $\left(G_{\mid \max }\right.$ of $\left.290 \mathrm{~J} / \mathrm{m}^{2}\right)$, the crack growth rate decreases to $10^{-6} \mathrm{~mm} /$ cycles in approximately 120,000 cycles.

Figure 6 summarises all the re-loading steps for the various Z-pinned samples (both $2 \%$ and $4 \%$ pinning densities). The crosses or open symbols are plots obtained from testing $4 \%$ pin density specimens whereas the filled symbols are specimens reinforced at $2 \%$ pin density. It has to be noted that the position of the deceleration (in terms of applied load) depends on the applied load, but not on the density of reinforcement. This is explained by the fact that if the reinforcement is sufficient to decelerate the crack propagation rapidly, the crack length does not vary significantly, therefore $G_{I \max }$ is controlled by the applied load $P_{\max }$.

When the loading is sufficient, or if the crack front has reached the end of the pinned area, the bridging actions of the pins become insufficient to slow down the crack propagation. The crack growth rate increases rapidly and the specimens fail by delamination through their entire length within a few cycles. This critical load is $170 \mathrm{~N}\left(G_{\mathrm{imax}}=2.1 \mathrm{~kJ} / \mathrm{m}^{2}\right)$ for the specimen reinforced with Z-Pins at a density of $2 \%$. 
The final failure occurred by delamination along the length when the load was increased from $200 \mathrm{~N}$ to $250 \mathrm{~N}$. In contrast to the quasi-static test, the delamination propagated through the Z-pinned area and no flexural failure of the loading arms was observed.

\subsubsection{Mode II}

For the Mode II ELS configuration it has been demonstrated that:

$\frac{\partial G_{I I}(a, \delta)}{\partial a} \leq 0 \Leftrightarrow\left(\frac{a}{L}\right) \geq \sqrt[3]{6} \approx 0.55$

and

$\frac{\partial G_{I I}(a, P)}{\partial a} \geq 0$ always.

Using the same argument as for the Mode I fatigue delamination tests, in load control experiments, as the crack propagates under cycling at constant $P_{\max }$, the applied $G_{\| \max }$ increases. In displacement control experiments, the applied $G_{\| \max }$ decreases, provided that the ratio $(a / L)$ is greater than 0.55 (i.e., relatively long crack length).

Figure 7 shows plots of crack growth rate versus applied $G_{\| \max }$ for both control and 2\% Zpinned specimen.

Due to the difference in loading conditions, it appears that there is a difference in trend between displacement control (full circles) and load control loading (full triangles) conditions. However, due to the differences in applied load, it is difficult to know if the two curves are connected.

The behaviour of the $2 \%$ Z-pinned specimen is similar to that observed in Mode I fatigue testing of Z-pinned laminates. Under load control conditions, the bridging actions of the pins slow down the crack propagation. Subsequently, each time the load was increased, the crack propagation re-started, but then slowed down again due to the actions of the pins. The tests were stopped when the crack had reached the clamping fixture.

\section{Discussion}

\subsection{Data analysis of specimens containing through-thickness reinforcement - quasi-static}

As all the samples were manufactured at the same time and cut out from one large panel, it is expected that the toughness of the un-reinforced portions of the samples should be fairly reproducible. A closer observation of the resistance curves of the quasi-static tests shown in Fig. 2 reveals relatively large scatter in $G_{1 C}$ values corresponding to a crack propagating in the first $15 \mathrm{~mm}$ from the insert (i.e., in the un-reinforced area of the specimens; see Table 1). 
This large scatter may indicate that the corrected beam theory analysis, as described in ISO 15024 , may not be applicable to the analysis of DCB specimens containing through the thickness reinforcement. Using the procedure recommended in the ISO standard, the crack length correction factor $\Delta$ is the intercept of the plot of $(C / M)^{1 / 3}$ versus $a$, the crack length. The standard procedure uses all data points available except the initiation points. From Table 1 it is apparent that the crack length correction factors $\Delta$ tend to be higher with higher pin density. The scatter in $\Delta$ also increases. The large scale bridging due to the pins will have the effect of modifying the apparent compliance of the beam, therefore $\Delta$ will be affected. The backcalculated E-moduli, related to $\Delta$, show similar scatter and differ significantly from the value obtained from an independent measurement in a three-point bending test. This is an indicator of the need to use an alternative data reduction method.

Due to the specimen configuration, the delamination grows in three different bridging stress environments. First, the crack grows in an unpinned area. The bridging stresses in the crack wake are limited to the 'natural' fibre bridging occurring in standard unidirectional laminates. Second, the crack enters the pinned area, and large scale bridging begins to develop. The load increases, the apparent delamination resistance also increases. This is termed 'the developing zone' by Robinson and Das [23]. Third, the bridging zone is fully developed as the crack advances through the pinned area. The number of pins acting in the crack wake is constant, as illustrated in Fig. 8 [2]. This may be termed the 'developed zone'.

Robinson has demonstrated that the corrected beam theory analysis provides consistent toughness values for the developed zone provided that the data are analysed in a slightly different way: The crack length correction factors $\Delta_{\text {developed }}$ must be calculated using data points from the fully developed zone only [23]. Similarly, the toughness values of the unpinned area should also be analysed using data points from unpinned area only. This analysis has been implemented and the results are summarised in Table 2. For the unpinned area (first $15 \mathrm{~mm}$ without initiation points) the $\Delta_{15 \mathrm{~mm}}$ correction factors range from 0 to $31 \mathrm{~mm}$. The corresponding toughness values now range from 215 to $318 \mathrm{~J} / \mathrm{m}^{2}$. There are a number of possible reasons for this large scatter.

Firstly, the regression analysis for the calculation of $\Delta_{15 \mathrm{~mm}}$ is carried out on a limited number of points, typically between 5 and 8 . The range of different crack extension lengths where this regression is performed is also very limited (typically 2 to $13 \mathrm{~mm}$ ). These two factors will increase the uncertainty of the calculation of the correction factors; a small error in crack length measurement results in a large error in the final $\Delta$. The same approach has been used to calculate the toughness in the plateau area. Table 2 shows that there is a large scatter in the $\Delta_{\text {developed }}$ values. This, in turn, introduces a scatter in the toughness values of the plateau region (from $4.1 \mathrm{~kJ} / \mathrm{m}^{2}$ to $5.6 \mathrm{~kJ} / \mathrm{m}^{2}$ ) which was not apparent when the data were analysed using corrected beam theory. Besides the problems explained above for the calculation of $\Delta_{15 \mathrm{~mm}}$, there is the added problem of unstable, stick-slip behaviour often encountered in the pinned area. Stick-slip behaviour in unpinned laminates usually results in so-called arrest 
values (with very low apparent toughness) which shall be excluded from the analysis according to the ISO 15024 standard. In Z-pinned laminates, whilst the arrest values may not be easy to identify, their exclusion would further reduce the number of data points and increase the difficulty in the extrapolation for $\Delta$.

In order to determine the crack bridging stresses and damage mechanisms occurring in a DCB test, Brunner et al. developed an analysis scheme based on compliance (i.e, machine data) and independently determined E-modulus. This scheme, described in [24] relies on equation 2 for the determination of $\mathrm{G}_{\mathrm{IC}}$.

$$
G_{I C}=\left(\frac{3 P \delta}{b h}\right) \cdot \frac{1}{\left(\frac{C}{N} E_{1} b\right)^{1 / 3}} \quad \text { (equation 2) }
$$

It is to be noted that the crack length does not appear in this equation; an intrinsic effective crack length is used from the measurement of the compliance during the test and the knowledge of the flexural modulus of the beam. The average flexural modulus of AS4B/8552 was determined independently from 3 pt bend tests as 120GPa. The stiffness of laminates containing Z-pins was found to be the same as that of the un-reinforced material.

This analysis was implemented assuming that the true compliance of the beam is not affected by the presence of the through-thickness reinforcement. The results are presented in Table 3. Using this analysis, the scatter in the toughness values of the unpinned area is reduced further ( $G_{I C}$ from 275 to $330 \mathrm{~J} / \mathrm{m}^{2}$ ). The scatter in the 'developed toughness' values is also reduced. However, the analysis leads to less conservative values of the apparent toughness. The use of finite element tools to investigate further the validity of the different approaches would lead to a better insight into which analysis to use for delamination tests of laminates containing through-thickness reinforcement.

\subsection{Overall failure mode of the specimens (static versus fatigue $4 \%$ )}

When the pin density is increased to $4 \%$, quasi-static tests (displacement control) showed a distinct change in failure mechanism, from delamination to flexural failure of the beam. The delamination was thus stopped inside the Z-pinned area. In load-controlled fatigue tests, this was not the case and the specimen failed by delamination.

In order to understand the cause of the failure of the DCB specimens, maximum compressive stresses in the upper plies of the arms are calculated using simple beam theory (see Table 4). This analysis reveals that during quasi-static testing of the control specimen, the maximum compression stress is approximately $200 \mathrm{MPa}$. This stress increases dramatically with the presence of through-thickness reinforcement. A stress in the order of $1000 \mathrm{MPa}$ is reached during steady state delamination of $2 \%$ pin reinforced specimens. At the time of failure, the stress in $4 \%$ specimen exceeds $1500 \mathrm{MPa}$. This value is close to the theoretical compression strength of this type of material. 
During fatigue testing, the loads applied range from $50 \mathrm{~N}$ to $250 \mathrm{~N}$. This translates to a maximum stress of $140 \mathrm{MPa}$ in the control specimens, $500 \mathrm{MPa}$ in the $2 \%$ specimens and $660 \mathrm{MPa}$ in the $4 \%$ samples. These stress levels are sufficiently low to prevent/avoid flexural failure of the beam.

Flexural failure depends on the maximum compression stress reached in the upper (or lower) plies of the beam. The presence of the through-thickness reinforcement will increase the stress in the component by resisting crack; simultaneously, the through-thickness reinforcement will reduce the compressive strength of UD laminates, therefore promoting early failure. The use of numerical tools should allow the prediction of the mode of failure of structures containing through-thickness reinforcement to be made, provided that the actions of the pins are modelled appropriately.

\subsection{Pin damage mechanisms (static versus fatigue) - Mode I}

Early optical observation of the broken samples revealed a change of pin damage mechanisms between quasi-static and fatigue failures (see Fig. 9 and Fig. 10) Dai et al. [28] have shown that during quasi-static testing of a Z-pinned DCB, the bridging process contains three stages: first elastic stretch of the Z-pin, then debonding and finally pullout controlled by friction. For perfectly oriented pins (close to $90^{\circ}$ from vertical), the damage to the pins is believed to be small. In this study the use of a caul plate during manufacture resulted in a final Z-pin angle close $30^{\circ}$. This strongly affects the bridging process and the ultimate failure of the pins. The higher magnification SEM of figure 11 shows in more detail the different pin damage mechanisms apparent after quasi-static testing. While some complete pin pullout is visible (Fig $11 \mathrm{a}$ ), there is evidence of pins failing in tension and bending (Fig. $11 \mathrm{~b}$ ). This is explained by the fact that pins inserted at an angle will be subjected to significant bending during the pullout phase.

Looking at DCB specimens fractured by fatigue loading, none or very little sign of pin pullout is noted (see Fig. 3c and Fig. 10). This suggests that different failure mechanisms occur (see Fig. 12). The fracture surface of the pin is quite planar and transverse to the Z-pin axis. The mechanisms promoting this failure mode are not well understood. It is likely that during delamination fatigue, the Z-pins will also be loaded in axial tension-compression fatigue as, during the loading phase of a cycle, tensile forces act on the pins. However, during the unloading phase, the pins are pushed back into the laminate, and compression stresses are set-up. The pin fracture plane is close to the fracture plane of the DCB specimen and there is no evidence of compression failure or buckling of the pin. This Z-pin fatigue failure mechanism has not been reported previously and is of significant importance to the prediction of fatigue life of a Z-pinned structure. Zhang et al. [29] reported a different Z-pin behaviour 
from cyclic pullout testing of blocks of pins. The determination of the correct bridging action will be the key to an accurate life prediction of Z-pinned structures.

\subsection{Displacement versus load control fatigue testing of Z-pinned laminates}

For Mode I fatigue tests, displacement control is preferred to load control ([30]). However, fatigue tests on Z-pinned laminates reported in this study have been carried out under load control. This mode of loading was chosen for two main reasons: -

First, this increasing $G_{I \max }$ loading with increasing crack length was preferred as any crack growth slow down can only be attributed to the actions of the Z-pins.

Second, load control was chosen to avoid the so called 'wedging effect' reported by Graftieaux et al. [31].

Under displacement control, during the loading phase of a fatigue cycle, the pins are subjected to tensile load. During the unloading phase of the cycle, as the minimum displacement (fixed from the onset of the test) was reached, the pins were under compressive stresses. The closure of the crack mouth tends to push the pins back in their socket. Due to the shear lag effect, it was impossible to push the pins in completely. Graftieaux and coauthors observed that the debonded pins acted as a wedge in the wake of the crack resulting in a tensile stress field at the crack tip and negative minimum load values $P_{\text {MIN }}$ were recorded. Despite this observation, an improvement of fatigue crack growth is reported for both Mode I and Mode II loading conditions.

Under load control, the crack closing displacement during the unloading part of the cycle is stopped as soon as the bridging pins produce a resistance equivalent to $10 \%$ of the maximum load (for $R=0.1$ ). This action limits potential damage to pins and laminate due to compressive pin loading (e.g., pin bending or buckling). During this study, a significant increase of the minimum displacement associated with the minimum load (fixed from the onset of the test) was observed while the crack propagated through the pinned area, also indicating that the pins are not pushed back fully in their socket. The effects of displacement control and their dependence on the Z-pinning parameters (e.g., pin density) still require further investigation.

\section{Conclusions}

Local reinforcement of laminate beams by both $2 \%$ and $4 \%$ areal densities of Z-pins has been shown to slow down the fatigue crack propagation under Mode I and Mode II under load control conditions. Contrary to quasi-static tests, no change in failure mode is observed for $4 \%$ pin density under fatigue loading. 
Under Mode I loading conditions, the energy absorbing mechanisms related to the Z-pins are changed from pullout or tensile failure to planar transverse fracture with the change of loading conditions from quasi-static to fatigue.

At present, the only effect of the pin density increase from 2 to $4 \%$ is a change in the maximum fatigue load (from $170 \mathrm{~N}$ to $250 \mathrm{~N}$ for a $25 \mathrm{~mm}$ wide sample).

More Mode II and mixed Mode I/II testing is required in order to understand fully the behaviour of Z-pins during fatigue delamination. It is expected that the pin bridging action will degrade under cyclic loading. It is therefore possible that the fatigue crack propagation will reinitiate after a finite fatigue life.

\section{Acknowledgements}

The authors wish to thank Mr D. Völki at EMPA and Mr A Scott at Cranfield University for their technical support. The gift of the prepreg by Hexcel Composites (UK) is also gratefully acknowledged.

\section{References:}

[1] A.P. Mouritz, Review of z-pinned composite laminates, Composites Part A: Applied Science and Manufacturing, Volume 38, Issue 12, December 2007, Pages 2383-2397

[2] I K. Partridge, D D.R Cartié, Delamination resistant laminates by Z-Fiber® pinning: Part I manufacture and fracture performance, Composites Part A: Applied Science and Manufacturing, Volume 36, Issue 1, January 2005, Pages 55-64

[3] D D .R Cartié, M Troulis, I K Partridge, Delamination of Z-pinned carbon fibre reinforced laminates, Composites Science and Technology, Volume 66, Issue 6, May 2006, Pages 855861

[4] D D R Cartié, A J Brunner, I K. Partridge, Effects of mesostructure on crack growth control characteristics in z-pinned laminates ESIS publication 32, Volume 32, 2003, Pages 503-514

[5] D D.R Cartié, I K. Partridge, Delamination behaviour of Z-pinned laminates, European Structural Integrity Society, Volume 27, 2000, Pages 27-36 
[6] V Dantuluri, S Maiti., P.H Geubelle., R., Patel H Kilic, Cohesive modelling of delamination in Z-pin reinforced composite laminates, Composites Science and Technology Volume 67, Issue 3-4, 2007, pp. 616-631

[7] M Grassi, X Zhang, Finite element analyses of mode I interlaminar delamination in z-fibre reinforced composite laminates, Composites Science and Technology, Volume 63, Issue 12 , September 2003, Pages 1815-1832

[8] W Yan, H-Y Liu, Y-W Mai, Mode II delamination toughness of z-pinned laminates, Composites Science and Technology, Volume 64, Issues 13-14, October 2004, Pages 19371945

[9] W Yan, H-Y Liu, Y-W Mai, Numerical study on the mode I delamination toughness of Zpinned laminates, Composites Science and Technology, Volume 63, Issue 10, August 2003, Pages 1481-1493

[10] J Teng, Z Zhuang, B Li, A study on low-velocity impact damage of z-pin reinforced laminates, Journal of Mechanical Science and Technology Volume 21 Issue 12, 2007, pp. 2125-2132

[11] X Zhang, L Hounslow, M Grassi, Improvement of low-velocity impact and compressionafter-impact performance by z-fibre pinning, Composites Science and Technology, Volume 66, Issue 15, 1 December 2006, Pages 2785-2794

[12] D DR Cartié, G Dell'Anno, E Poulin, I K. Partridge, 3D reinforcement of stiffener-to-skin T-joints by Z-pinning and tufting, Engineering Fracture Mechanics, Volume 73, Issue 16, November 2006, Pages 2532-2540

[13] P. Chang, A.P. Mouritz, B.N. Cox, Properties and failure mechanisms of pinned composite lap joints in monotonic and cyclic tension, Composites Science and Technology, Volume 66, Issue 13, October 2006, Pages 2163-2176

[14] M. Grassi, B. Cox, X. Zhang, Simulation of pin-reinforced single-lap composite joints, Composites Science and Technology, Volume 66, Issues 11-12, September 2006, Pages 1623-1638

[15] P. Chang, A.P. Mouritz, B.N. Cox, Flexural properties of z-pinned laminates Composites Part A: Applied Science and Manufacturing, Volume 38, Issue 2, February 2007, Pages 244-251 
[16] P. Chang, A.P. Mouritz, B.N. Cox, Properties and failure mechanisms of z-pinned laminates in monotonic and cyclic tension, Composites Part A: Applied Science and Manufacturing, Volume 37, Issue 10, October 2006, Pages 1501-1513

[17] A.P. Mouritz, Tensile fatigue properties of $3 \mathrm{D}$ composites with through-thickness reinforcement, Composites Science and Technology, Volume 68, September 2008, Pages 2503-2510

[18] A.P. Mouritz, Compression properties of z-pinned composite laminates, Composites Science and Technology, Volume 67, Issues 15-16, December 2007, Pages 3110-3120

[19] CA Steeves, NA Fleck. In-plane properties of composite laminates with through-thickness pin reinforcement. Int J Solids Struct 2006;43:3197-212.

[20] Anon LK. z-Pins strengthen the Super Hornet, save weight and cost. The Integrator 2001;3:1-2.

[21] McBeath S. Safety pins. Racecar Engineering 2002:56-62.

[22] ISO International Standard 15024, 2001, Fibre-reinforced plastic composites Determination of mode I interlaminar fracture toughness, $G_{I C}$, for unidirectionally reinforced materials, International Organisation for Standardization.

[23] P Robinson, S Das, Mode I DCB testing of composite laminates reinforced with zdirection pins: a simple model for the investigation of data reduction strategies, Engineering Fracture Mechanics, Volume 71, Issue 3, February 2004, Pages 345-364

[24] A.J.Brunner, B.R.K.Blackman, J.G. Williams: Calculating a damage parameter and bridging stress from GIC delamination tests on fibre composites, Composites Science and Technology Vol. 66, Issue 6, pp. 785-795 (2006)

[25] ESIS TC4, Determination of Mode I Fatigue Delamination Propagation in Unidirectionally Reinforced Materials (2005).

[26] ESIS TC4, Fibre-composites - The determination of the mode II fracture resistance, $\mathrm{G}_{\| \mathrm{IC}}$, of unidirectional fibre-composites using the calibrated end loaded split (C-ELS) test and an effective crack length approach (September 2008). 
[27] B.R.K Blackman., A.J Brunner., J.G Williams,.., Mode II fracture testing of composites: a new look at an old problem, Engineering Fracture Mechanics, Vol. 73, Issue 16, 2006, pp. 2443-2455.

[28] S-C Dai, W Yan, H-Y Liu, Y- W Mai, Experimental study on z-pin bridging law by pullout test, Composites Science and Technology, Volume 64, Issue 16, December 2004, Pages 2451-2457

[29] A-Y Zhang, H-Y Liu, A P. Mouritz, Y-W Mai, Experimental study and computer simulation on degradation of z-pin reinforcement under cyclic fatigue, Composites Part A: Applied Science and Manufacturing, Volume 39, Issue 2, February 2008, Pages 406-414

[30] A.J Brunner., N Murphy., G., Pinter Development of a standardized procedure for the characterization of interlaminar delamination propagation in advanced composites under fatigue mode I loading conditions, Engineering Fracture Mechanics 2009; Volume 76, pages 2678-2689.

[31] B Graftieaux, A Rezai, I Partridge. Effects of z-pin reinforcement on the delamination toughness and fatigue performance of unidirectional AS4/8552 composite. In: Proceedings of ECCM-9, Brighton,UK; June 2000. 


\section{Figures:}

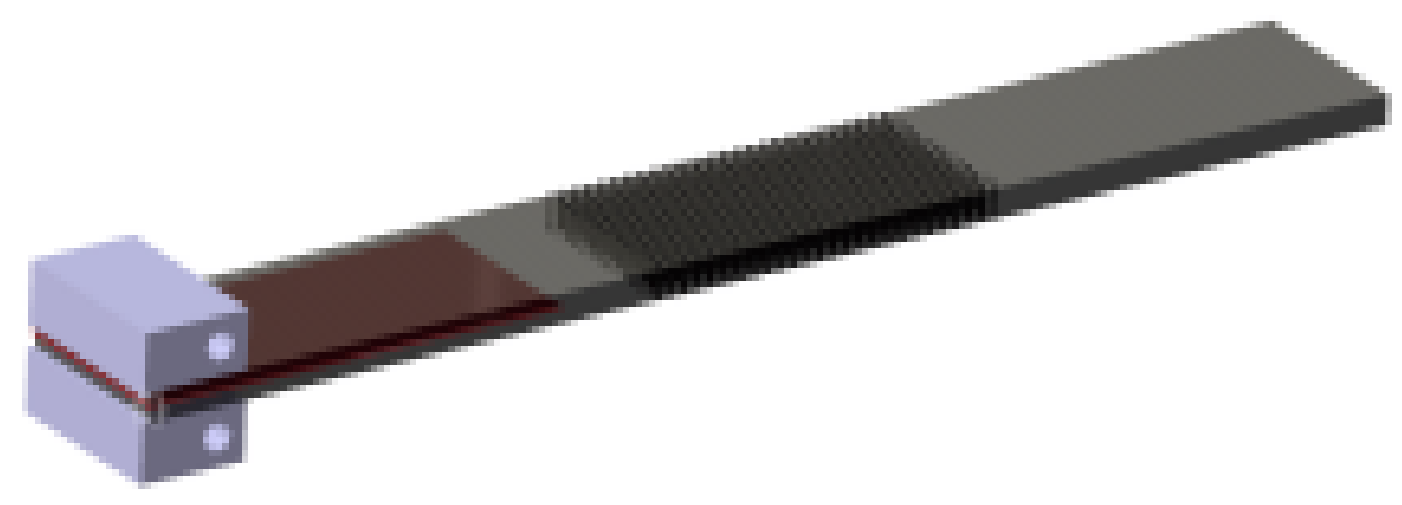

Figure 1: Specimen configuration

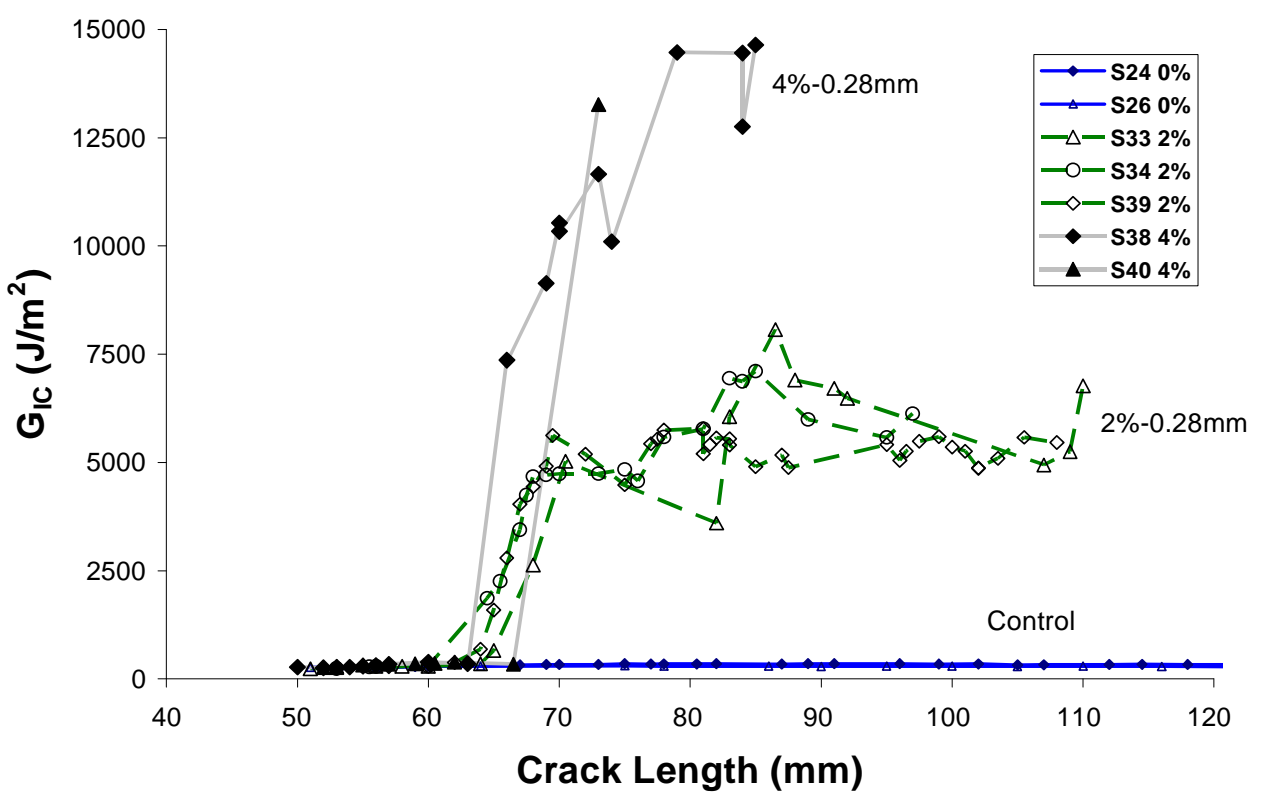

Figure 2: R-curves from quasistatic Mode I tests on unpinned and Z-pinned DCB specimens

(a) 


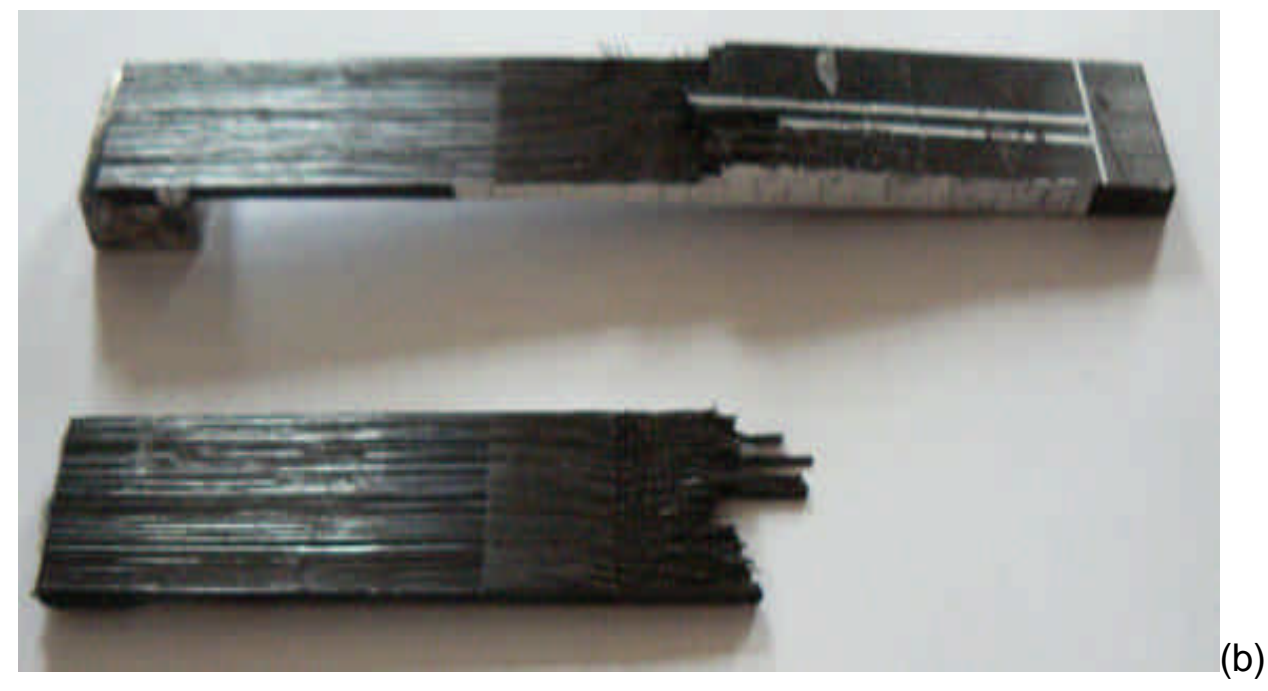

(c)

Figure 3: Photographs of a delamination crack propagating in 2\%-DCB specimen (a), $4 \%-$ DCB specimen failed by flexure under quasi-static load (b), and 4\%-DCB specimen failed by delamination under load-control fatigue (c)

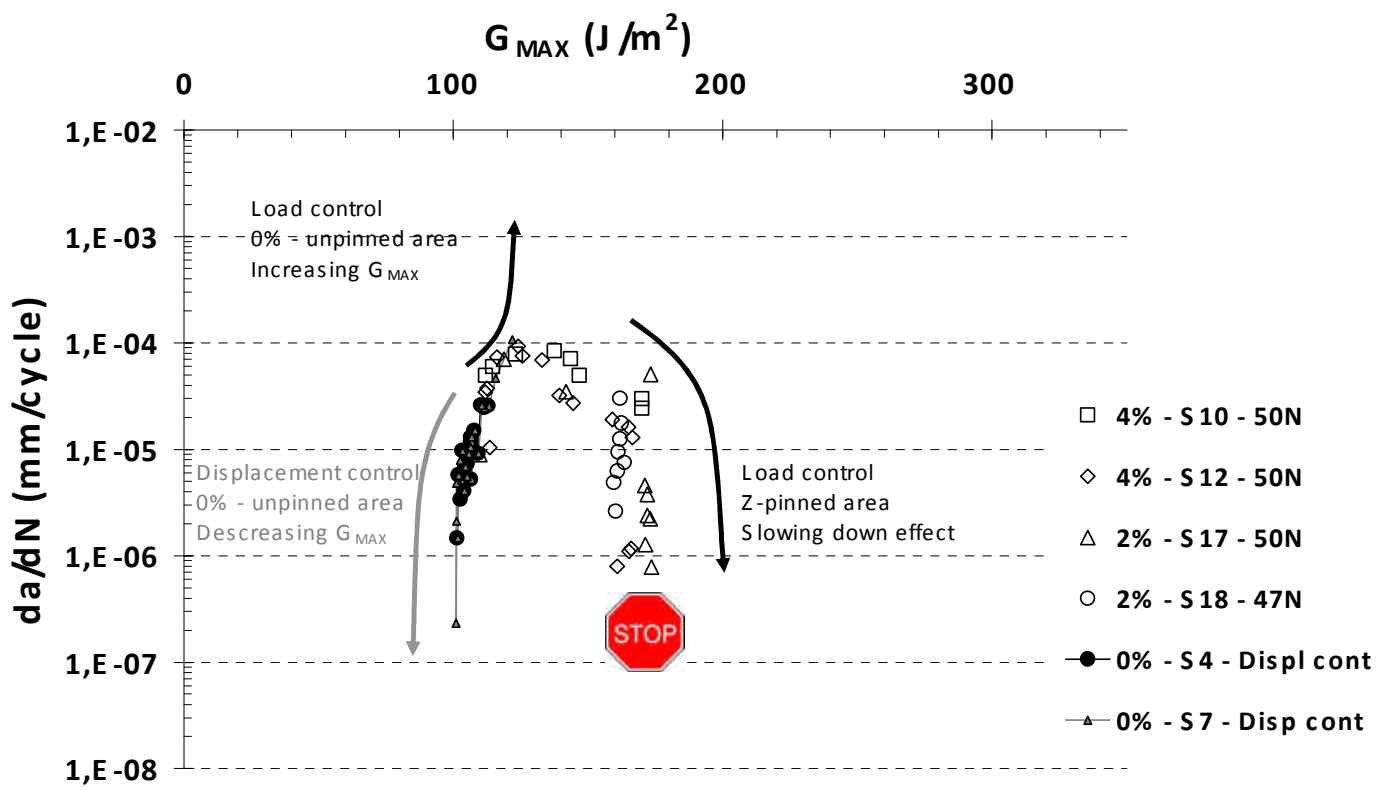

Figure 4: Mode I delamination fatigue crack growth rates. Control samples are tested under displacement control conditions, Z-pinned samples are tested under load control conditions with $\mathrm{P}_{\mathrm{MAX}}=50 \mathrm{~N}$. 


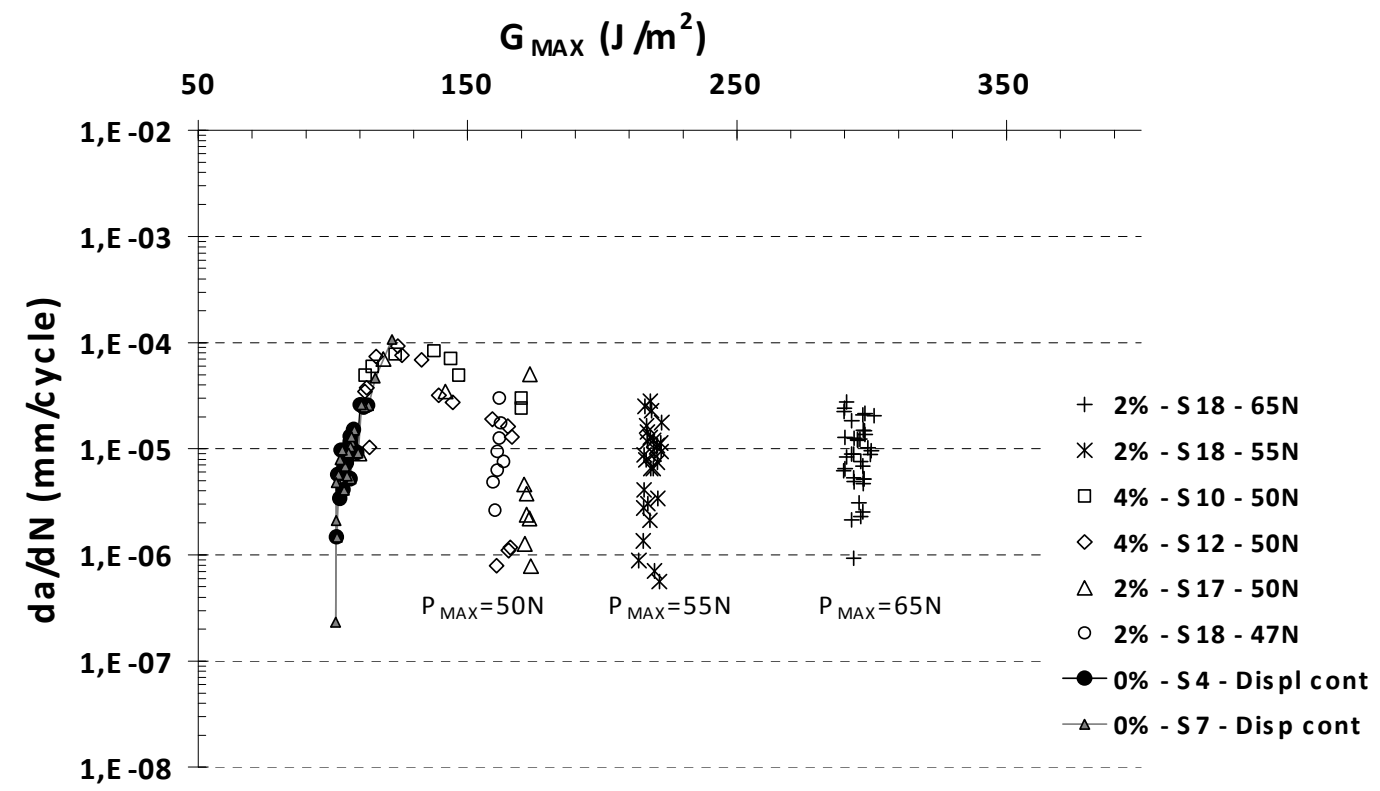

Figure 5: Mode I delamination crack growth rates maximum loads increments

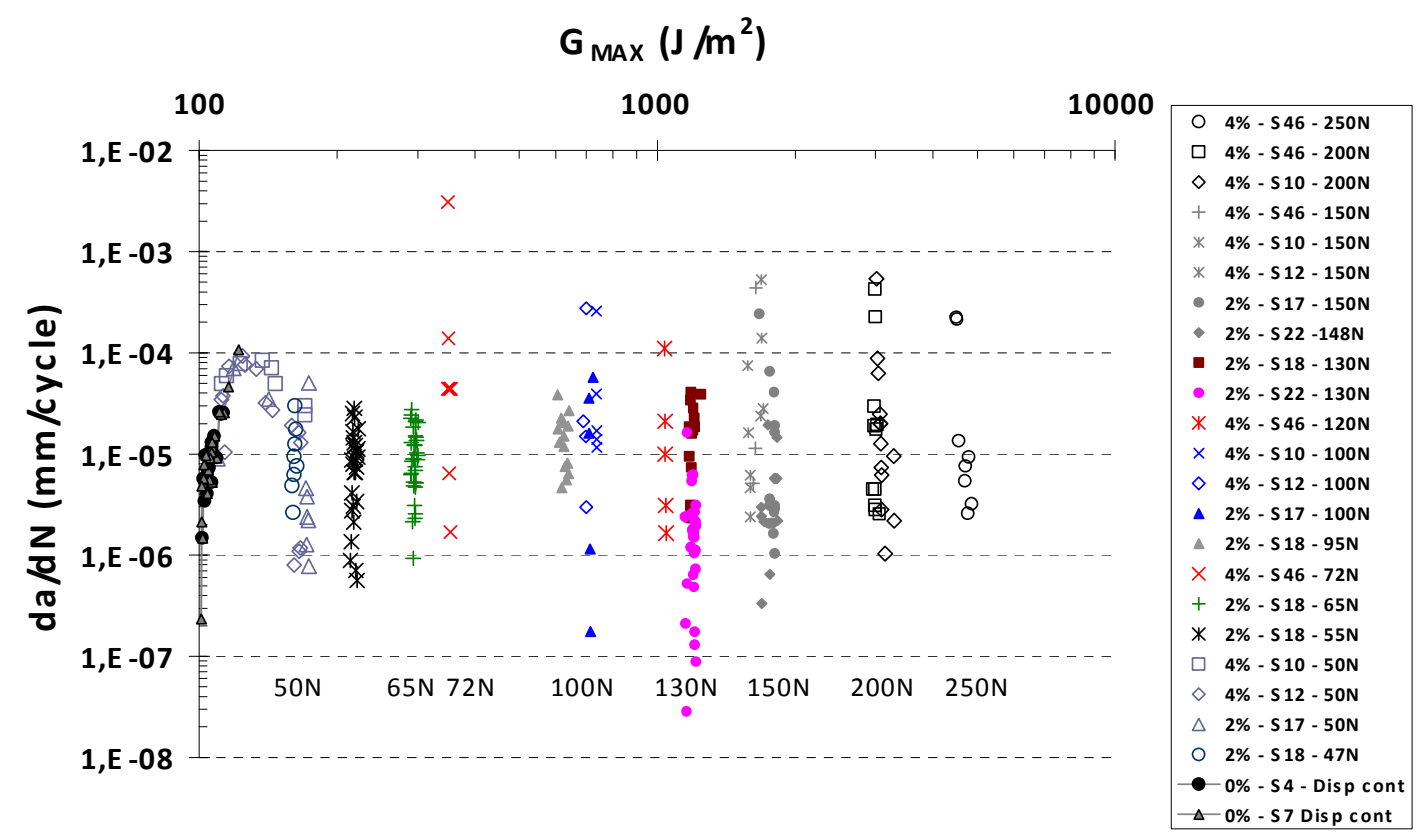

Figure 6: Mode I delamination crack growth rates, all data. (N.B. X-axis is on logarithmic scale) 


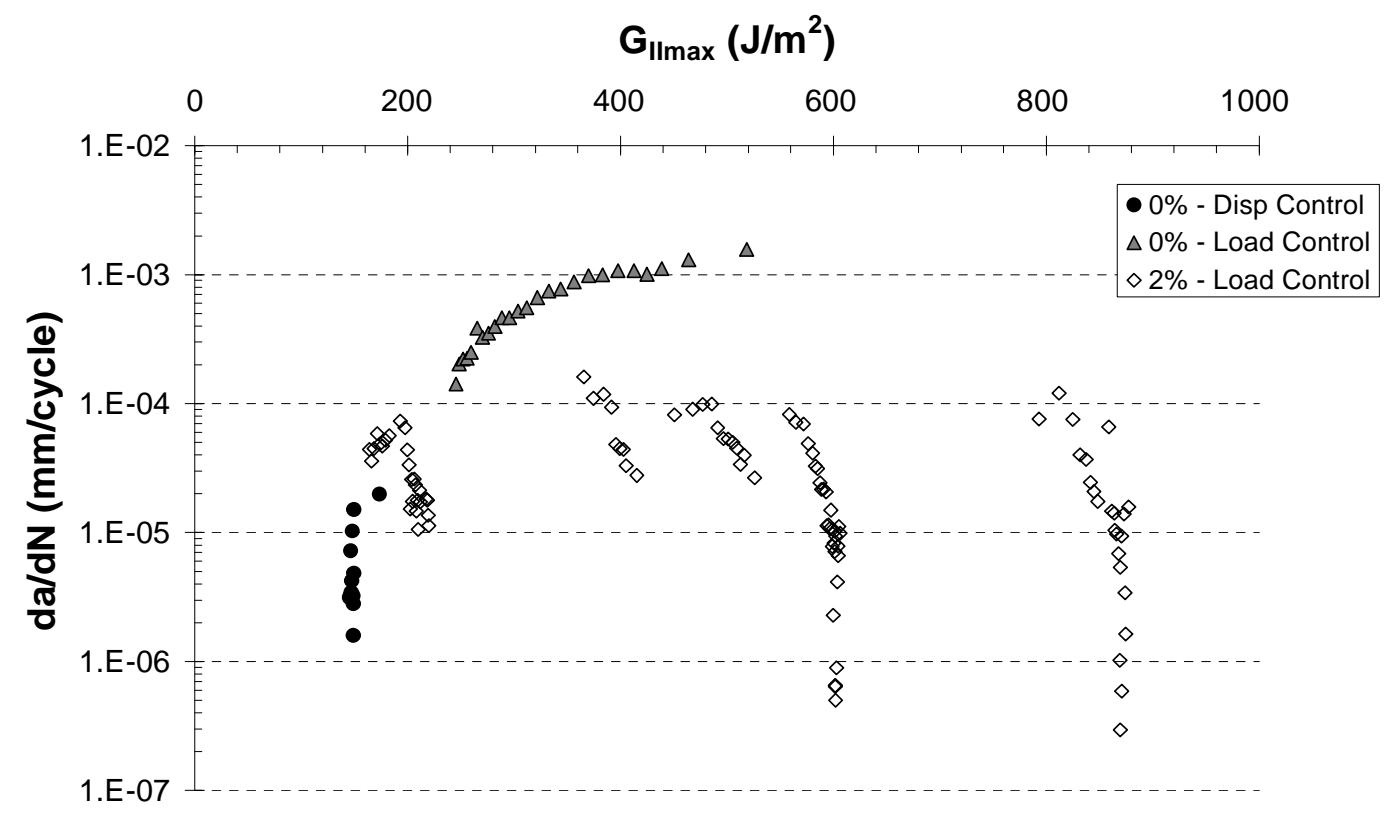

Figure 7: Mode II delamination crack growth rates for a control specimen and a $2 \%$ pinned specimen

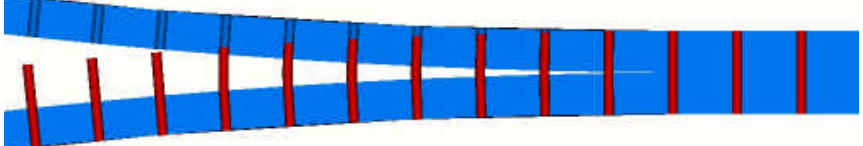

Figure 8: Schematic of steady state crack propagation in a Z-pinned specimen; the number of pins bridging the crack becomes constant. 


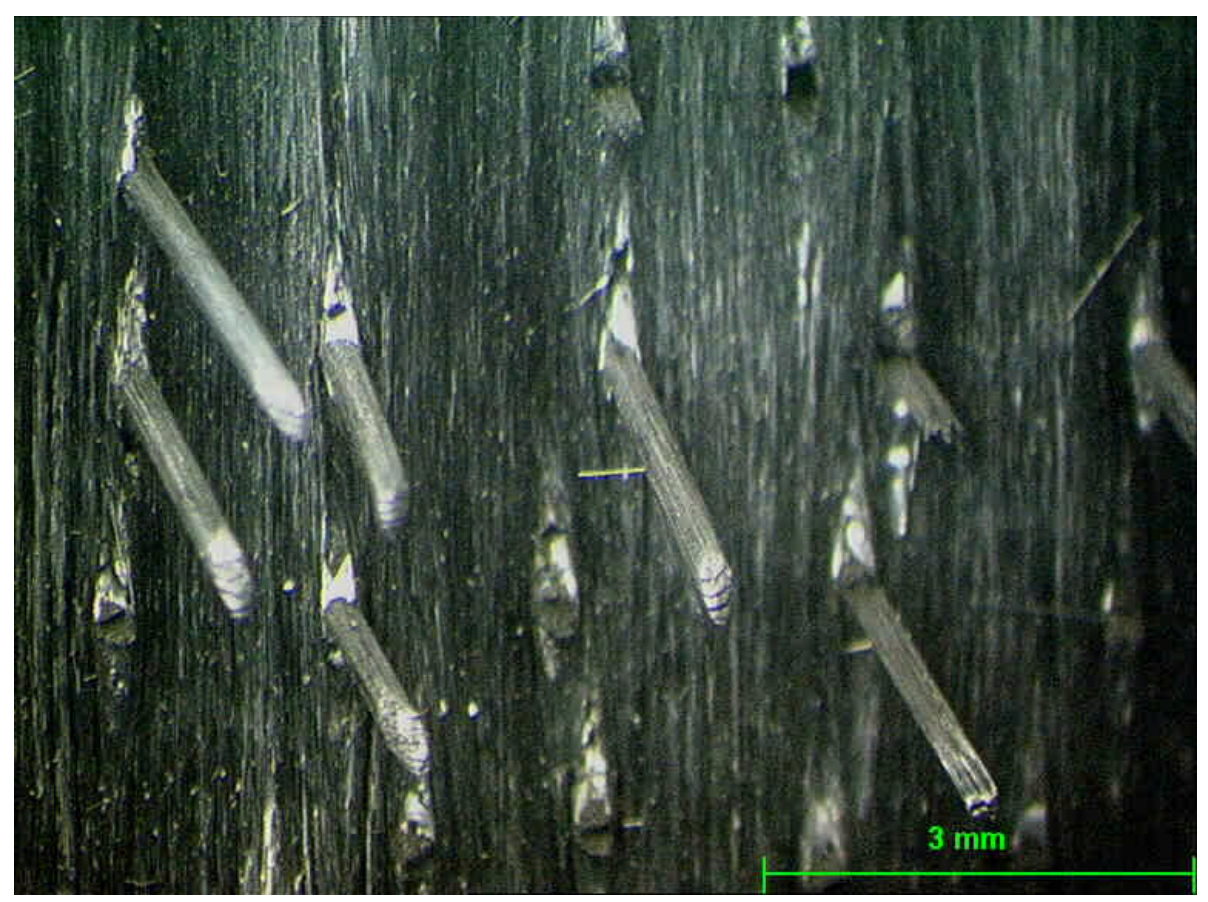

Figure 9: Optical Microscopy of the fracture surface showing Z-pins after a quasi-static Mode I test

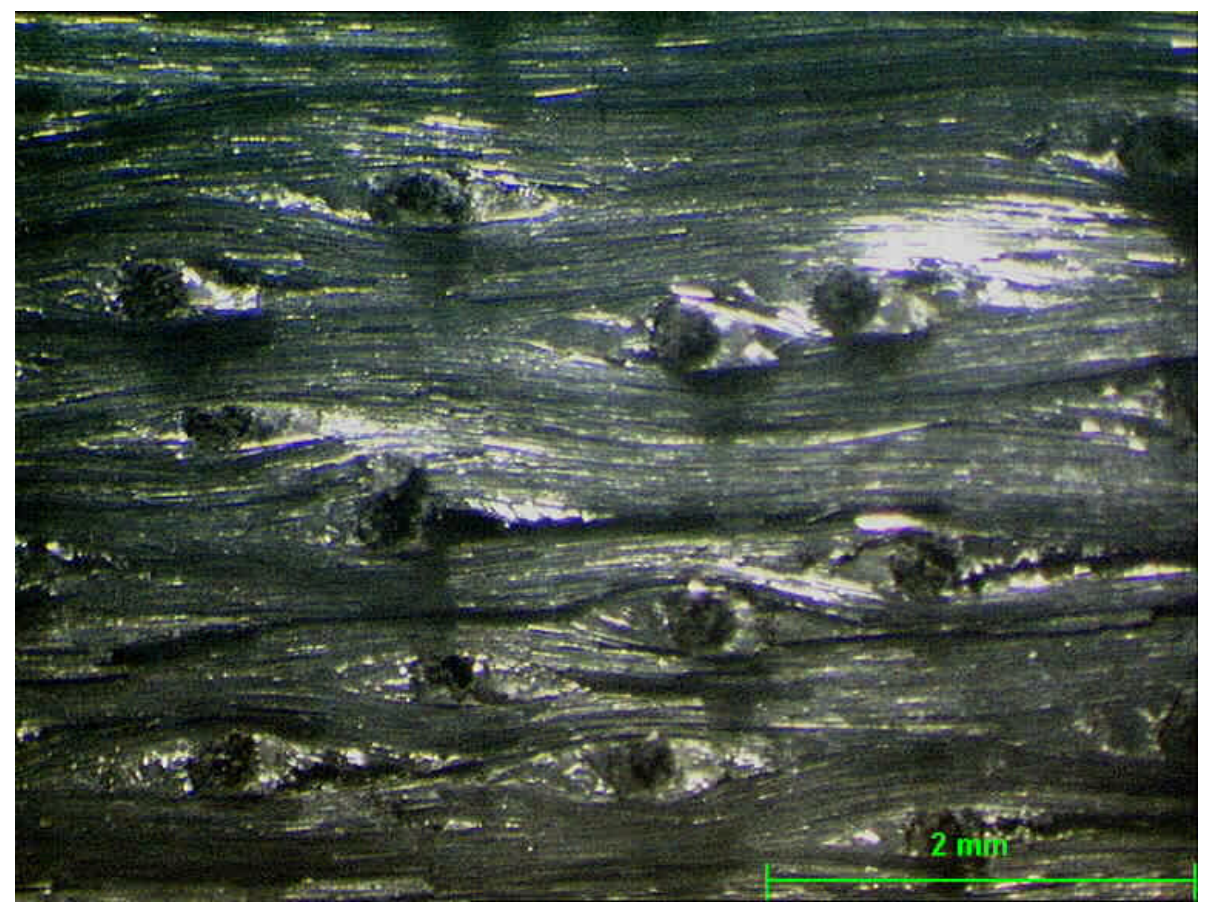

Figure 10: Optical Microscopy of the fracture surface after a Mode I fatigue test 


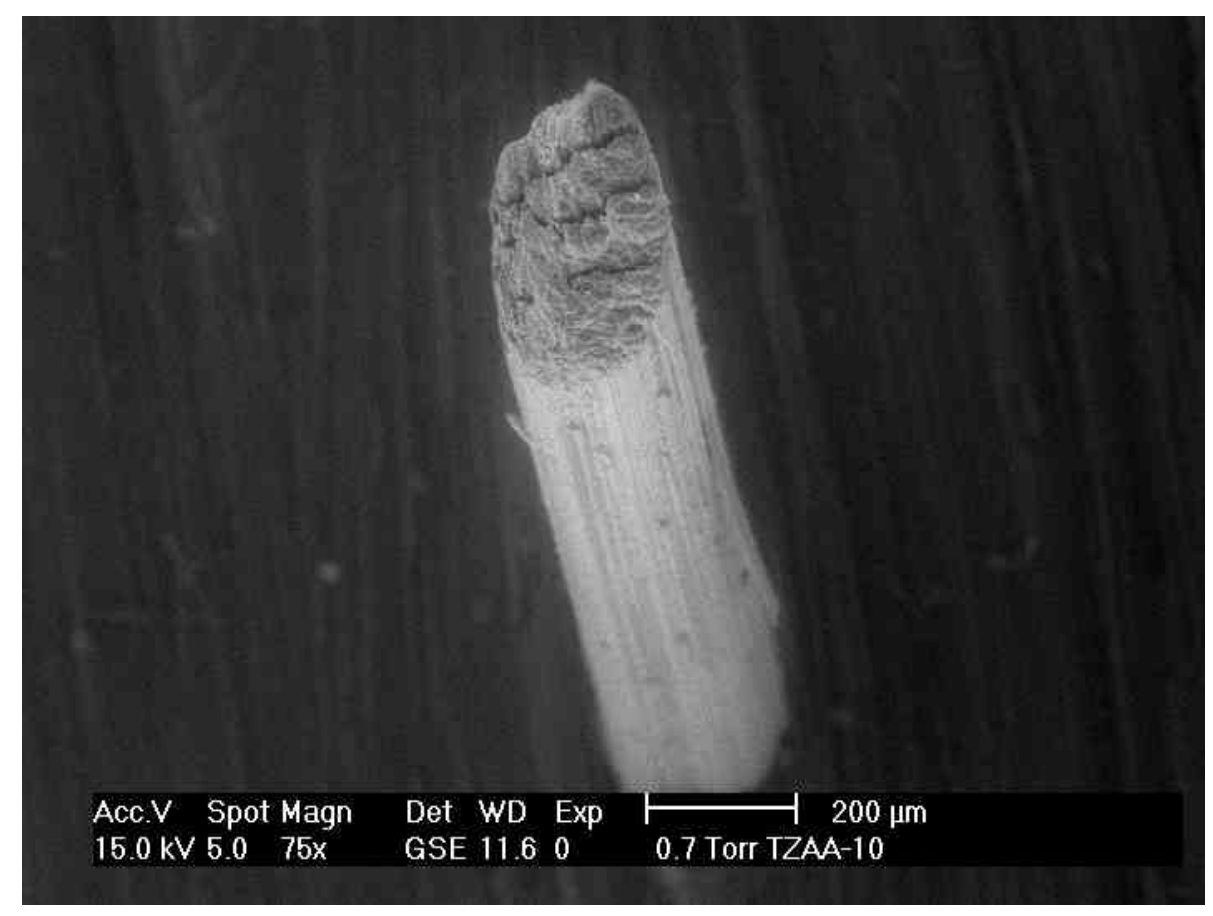

Figure 11 a: SEM of Z-pin after quasi-static testing showing complete pin pullout

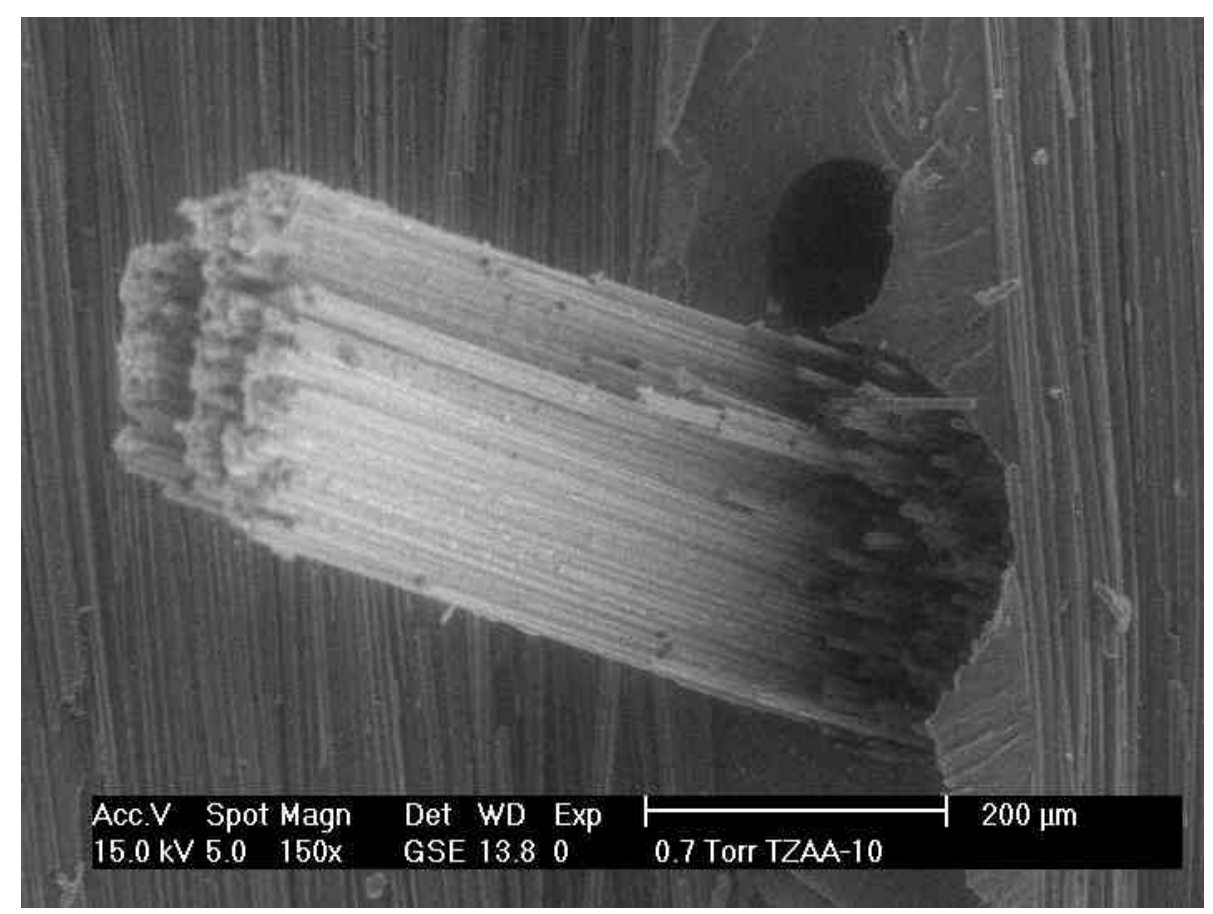

Figure $11 \mathrm{~b}$ : SEM of Z-pin after quasi-static testing showing signs of tensile/bending failure in the pin 


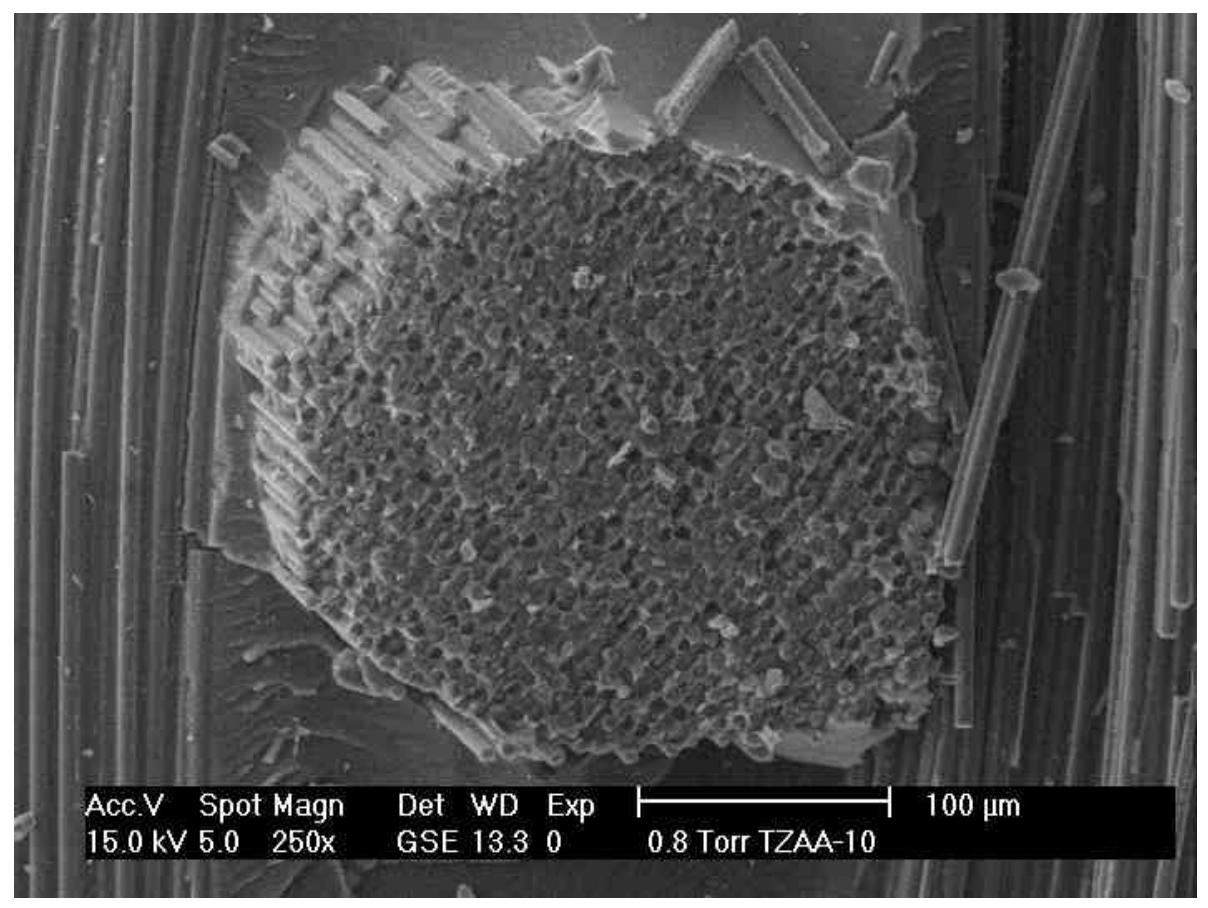

Figure 12: SEM of a pin after Mode I fatigue testing of a specimen reinforced with $2 \%$ Z-pins 


\section{Tables:}

Table 1: Corrected beam theory analysis of Mode I quasi-static tests

\begin{tabular}{|c|c|c|c|c|c|c|c|}
\hline & & \multicolumn{3}{|c|}{ CBT all points } & \multirow[b]{2}{*}{$\begin{array}{l}\mathrm{G}_{\mathrm{IC}} \text { ini } \\
{\left[\mathrm{J} / \mathrm{m}^{c}\right]}\end{array}$} & \multirow[b]{2}{*}{$\begin{array}{c}\mathrm{G}_{\mathrm{IC}} \text { Unpinned Area } \\
{\left[\mathrm{J} / \mathrm{m}^{\complement}\right]}\end{array}$} & \multirow[b]{2}{*}{$\begin{array}{c}\mathrm{G}_{\text {IC Plateau }} \\
{\left[\mathrm{J} / \mathrm{m}^{<}\right]}\end{array}$} \\
\hline & & $\begin{array}{c}\Delta \\
{[\mathrm{mm}]}\end{array}$ & $\begin{array}{c}\mathrm{E} \\
{[\mathrm{GPa}]}\end{array}$ & \# pts & & & \\
\hline \multirow[t]{2}{*}{$0 \%$} & S24 & -9.1 & 134.4 & 30 & 226 & 315 & - \\
\hline & S26 & -5.6 & 112.1 & 18 & 276 & 295 & - \\
\hline \multirow[t]{3}{*}{$2 \%$} & S33 & -11.5 & 148.5 & 18 & 228 & 278 & 5471 \\
\hline & S34 & -10.6 & 143.7 & 22 & 229 & 262 & 4804 \\
\hline & S35 & -6.8 & 120.1 & 37 & 271 & 283 & 5033 \\
\hline \multirow[t]{2}{*}{$4 \%$} & S39 & -24.2 & 225.4 & 19 & 214 & 218 & 9722 \\
\hline & $\mathrm{S} 40$ & -22.9 & 220.8 & 9 & 210 & 270 & 10432 \\
\hline
\end{tabular}

Table 2: Analysis of Mode I Quasi-static tests using the approach of [23]

\begin{tabular}{|c|c|c|c|c|c|c|c|c|c|}
\hline & & \multicolumn{4}{|c|}{ CBT first $15 \mathrm{~mm}$} & \multicolumn{4}{|c|}{ CBT plateau only } \\
\hline & & $\begin{array}{c}\Delta \\
{[\mathrm{mm}]}\end{array}$ & $\begin{array}{c}\mathrm{E} \\
{[\mathrm{GPa}]}\end{array}$ & \# pts & $\begin{array}{l}\mathrm{G}_{1 \mathrm{C}} \text { ini } \\
{\left[\mathrm{J} / \mathrm{m}^{2}\right]}\end{array}$ & $\begin{array}{c}\mathrm{G}_{\mathrm{IC}} \text { Unpinned Area } \\
{\left[\mathrm{J} / \mathrm{m}^{2}\right]}\end{array}$ & $\begin{array}{c}\Delta_{\text {Developed }} \\
{[\mathrm{mm}]}\end{array}$ & \# pts & $\begin{array}{c}\mathrm{G}_{\text {IC Plateau }} \\
{\left[\mathrm{J} / \mathrm{m}^{2}\right]}\end{array}$ \\
\hline \multirow[t]{2}{*}{$0 \%$} & S24 & -7.5 & 125.3 & 6 & 225 & 314 & - & - & - \\
\hline & S26 & -10.7 & 144.9 & 5 & 275 & 293 & - & - & - \\
\hline \multirow[t]{3}{*}{$2 \%$} & S33 & -31.8 & 320.9 & 6 & 172 & 215 & -9.5 & 10 & 5577 \\
\hline & S34 & -4.9 & 111.2 & 4 & 251 & 286 & -25.3 & 12 & 4128 \\
\hline & S35 & -14.4 & 157.0 & 4 & 241 & 253 & -2.7 & 29 & 5228 \\
\hline \multirow[t]{2}{*}{$4 \%$} & S39 & -0.1 & 77.3 & 8 & 318 & 318 & -57.7 & 9 & 7317 \\
\hline & $\mathrm{S} 40$ & -17.8 & 181.1 & 8 & 225 & 288 & - & 1 & - \\
\hline
\end{tabular}

Table 3: Analysis of Mode I Quasi-static tests using the approach of [24]

\begin{tabular}{ccccc} 
& & \multicolumn{3}{c}{ Compliance method E=120GPa } \\
\cline { 3 - 5 } & & $\begin{array}{c}G_{I C} \text { ini } \\
{\left[\mathrm{J} / \mathrm{m}^{2}\right]}\end{array}$ & $\begin{array}{c}G_{I C} \text { Unpinned Area } \\
{\left[\mathrm{J} / \mathrm{m}^{2}\right]}\end{array}$ & $\begin{array}{c}G_{I C} \text { Plateau } \\
{\left[\mathrm{J} / \mathrm{m}^{2}\right]}\end{array}$ \\
\hline $0 \%$ & S24 & 236 & 329 & - \\
& S26 & 270 & 289 & - \\
$2 \%$ & S33 & 241 & 299 & 5981 \\
& S34 & 245 & 280 & 5189 \\
& S35 & 262 & 279 & 5141 \\
$4 \%$ & S39 & 275 & 275 & 12366 \\
& S40 & 260 & 331 & 13266 \\
\hline
\end{tabular}


Table 4: Maximum bending stress levels in the upper layer of the beams

\begin{tabular}{ccc} 
& $\begin{array}{c}\text { Static } \\
{[\mathrm{MPa}]}\end{array}$ & $\begin{array}{c}\text { Fatigue } \\
{[\mathrm{MPa}]}\end{array}$ \\
\hline $0 \%$ & 200 & $120-140$ \\
$2 \%$ & $950-1000$ & $490-500$ \\
$4 \%$ & $>1500$ & $640-660$
\end{tabular}

